DOI: 10.11606/issn.2238-3867.v15i2p198-210

sala preta

ppgac

Dossiê espetáculo: Christiane Jatahy

\title{
O teatro de Christiane Jatahy: formação intelectual e pesquisa artística
}

Christiane Jatahy's theater: intellectual development and artistic research

José Da Costa

José Da Costa

Professor associado da Universidade Federal do

Rio de Janeiro e pesquisador do CNPq

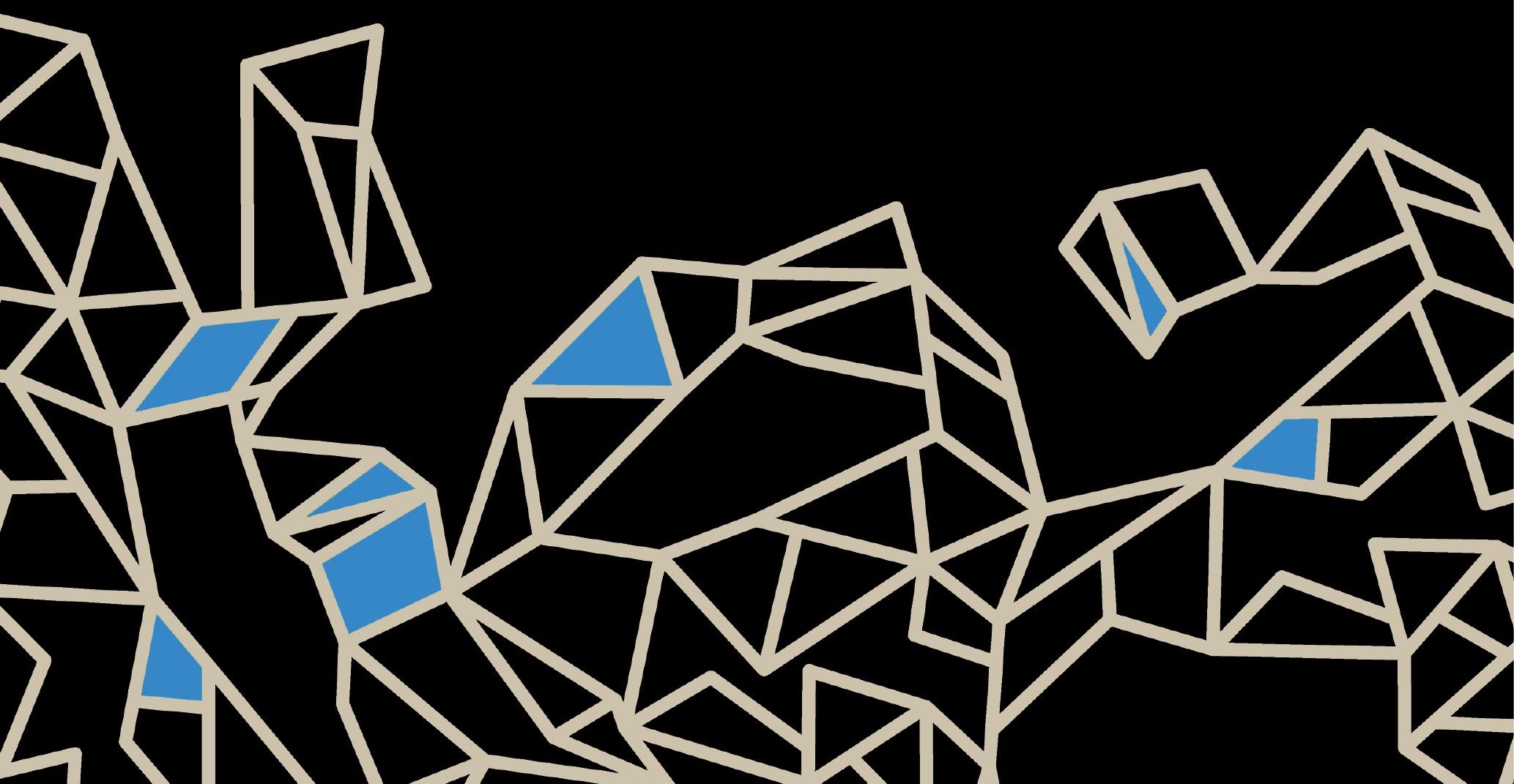




\section{Resumo}

Este artigo aborda, a princípio, alguns aspectos da formação e da trajetória artística da dramaturga e encenadora Christiane Jatahy, a partir dos anos 1990. Mas o objetivo mais específico deste texto é apresentar uma análise e uma reflexão crítica sobre o espetáculo $E$ se elas fossem para Moscou?, que a diretora estreou no Rio de Janeiro em 2014 e já apresentou em diferentes estados e em vários países, principalmente da Europa.

Palavras-chave: Christiane Jatahy, Teatro contemporâneo, Teatro carioca.

\section{Abstract}

This article discusses, at first, some aspects of intellectual development and artistic career of the playwright and stage director Christiane Jatahy since the 1990s. But a more specific goal of this paper is to present an analysis and a critical reflection on the show If they were to Moscow?, that the director debuted in Rio de Janeiro in 2014 and has already presented in different states and several countries, mainly in Europe.

Keywords: Christiane Jatahy, Contemporary theater, Carioca theater.

É como atriz que a diretora carioca Christiane Jatahy principia sua relação com o teatro e começa a formar seu gosto pela investigação artística. Foi também como intérprete que ela pôde, inicialmente, aprofundar-se nas propostas do dramaturgo espanhol José Sanchis Sinisterra, que passou a ser uma referência fundamental em sua formação artística e intelectual. $\mathrm{Na}$ década de 1990, ela atuou em várias peças do dramaturgo exibidas no Rio de Janeiro, como Naque, de piolhos e atores (1991), com direção do encenador Moncho Rodrigues; Ay, Carmela (1994), com o diretor Aderbal Freire Filho; e Perdida nos Apalaches (1997), encenada também pelo próprio Sinisterra. Logo após a primeira dessas três experiências como atriz, Christiane Jatahy participou, em 1992, de um curso ao longo de três meses, na Sala Beckett, em Barcelona, sob a direção pedagógica de Sinisterra, que se destinava à capacitação profissional de jovens dramaturgos e pessoas de teatro, de modo 
geral, com base no conhecimento de procedimentos formais da construção dramática, principalmente nas obras de autores do contexto do modernismo literário e das vanguardas ${ }^{1}$.

Pode-se dizer que foi nesse momento que Christiane teve contato com toda uma referência dos métodos estruturalistas e formalistas de análise literária, referência essa de que Sinisterra lançava mão fortemente em seu trabaIho no campo da pedagogia teatral, principalmente no que tange à formação de novos dramaturgos. O apuro da consciência da jovem artista sobre os procedimentos composicionais no âmbito da ficção literária, de caráter narrativo ou dramático, bem como o chamado à reflexão contínua sobre a relação sempre ambivalente da ficção com a vida e com a história, que são aspectos fundamentais do trabalho criativo de Christiane como diretora e como dramaturga, tiveram provavelmente sua gênese nesse contexto formativo. Contexto esse a partir do qual, aprofundaram-se também relações com outros dramaturgos, como com Sergi Belbel, igualmente ex-aluno de Sinisterra e de quem Christiane encenou, no Rio de Janeiro, a peça Carícias (2001).

Nas peças dirigidas a um público juvenil e criadas por Christiane Jatahy com o Grupo Tal, no Rio de Janeiro, na segunda metade dos anos 1990, já estava estabelecida a importante parceria com o arquiteto Marcelo Lipiane, que se tornou o cenógrafo e diretor de arte dos espetáculos da diretora. Naquelas experiências, a experimentação em relação aos espaços físicos em que se dá o evento teatral já era marcante no trabalho de Jatahy e Lipiane. As três encenações daquele período eram adaptações assinadas pela diretora: Peter Pan (1996), de J.M. Barrie; Alice (1998), de Lewis Carrol; e Pinóquio (1999), de Carlo Collodi.

O interesse sobre os recursos criativos que a apropriação de textos literários não escritos para o teatro poderiam fornecer já era um traço marcante no trabalho da dramaturga e diretora naqueles espetáculos. O conhecimento dos procedimentos criativos e das ideias de Sinisterra quanto à recriação dra-

1 O curso, de três meses de duração e com periodicidade anual, intitulava-se "Novas Tendências da Criação e da Produção Teatral" e aglutinava fundamentalmente jovens artistas latino-americanos a cada uma de suas edições. Eu mesmo participei, como aluno, com bolsa do Instituto de Cooperação Ibero-Americano, no ano de 1994, na Sala Beckett, em Barcelona, depois de ter sido apresentado a Sanchis Sinisterra por Christiane Jatahy, no Rio de Janeiro. 
matúrgica de obras de narrativa de ficção escritas por outros autores e não destinadas originalmente ao teatro foram, muito provavelmente, alguns dos fatores propulsores daqueles trabalhos de Jatahy². Aliás, as trocas intelectual e artística da criadora com Sinisterra nunca se interromperam e, em 2006, Jatahy dirigiu a peça do dramaturgo intitulada Leitor por horas, em espetáculo que estreia no Centro Cultural Banco do Brasil, no Rio de Janeiro.

É com a encenação de Conjugado (2004) que Jatahy começa a radicalizar uma série de questões associadas à relação entre a representação e a verdade, entre o jogo ficcional e a realidade, entre teatro e vida. Também o interesse pela forma de plasmar em cena a experiência do cotidiano pueril e banal teve aí o seu primeiro ponto de inflexão importante na trajetória artística de Jatahy. A peça mostrava uma personagem feminina solitária em seu apartamento conjugado, após ter chegado de um dia de trabalho, realizando, diante do público que a observa, suas atividades domésticas, pessoais e de lazer (trocar de roupa, tomar relaxantes, preparar-se para dormir, ver televisão, comer bombons etc.). O trabalho foi construído a partir de um processo de pesquisa que incluiu a coleta de muitos depoimentos de mulheres que vivem solitariamente. Agora, as entrevistas e depoimentos de pessoas anônimas, e não mais obras literárias, foram a base referencial que serviu de trampolim para o livre salto criativo no qual as dimensões documental e ficcional começavam a ter seus limites deliberadamente borrados na experimentação artística de Jatahy.

Todo esse interesse pela experiência do cotidiano e do banal como fonte de uma poesia cênica inusitada, bem como todo um impulso para investigar a região fronteiriça e ambígua entre ficção e realidade, invenção e depoimento, âmbito documental e puro jogo teatral estiveram presentes nos projetos seguintes. Um deles foi a peça $A$ falta que nos move ou todas as histórias são ficção (2005), que se desdobrou no filme $A$ falta que nos move, exibido em festivais de cinema e também no circuito cinematográfico, a partir de 2008. O outro projeto foi a peça Corte Seco, que teve sua temporada de es-

2 A produção dramatúrgica de Sinisterra é fortemente marcada pelo diálogo intertextual com a moderna narrativa de ficção. Contos e romances de Samuel Beckett, Herman Melville, Franz Kafka, James Joyce e Ernesto Sábato foram teatralizadas pelo dramaturgo, que também adaptou, para o teatro, narrativas de outros contextos históricos, a exemplo de relatos de viagem do período renascentista (COSTA FILHO, 1997). 
treia em 2009, no Espaço Sérgio Porto, no Rio de Janeiro. Nesses trabalhos, Christiane Jatahy investigou, de forma inteiramente clara, a fronteira entre os campos criativos do teatro e do cinema, fronteira essa que continuou sendo um território importante nas pesquisas teatrais da criadora em seus espetáculos seguintes, a exemplo de Julia, livre criação a partir de Senhoria Júlia, de Strindberg, construída como um diálogo intenso entre as linguagens do teatro e do cinema, uma vez que tanto havia filmes realizados previamente e exibidos durante o espetáculo, integrando o tecido estrutural da peça, como também havia captação de imagens ao vivo, mostrando trechos ocultos da ação, trechos que, muitas vezes, só eram visíveis para o espectador pela mediação da imagem³.

\section{O teatro-cinema}

No espetáculo $E$ se elas fossem para Moscou? ${ }^{4}$, com dramaturgia e encenação de Christiane Jatahy, foi escrita a partir da peça As três irmãs, de Anton Tchekhov. Na peça, vemos três personagens femininas em cena (Olga, Maria e Irina), em sua casa, na noite de comemoração do aniversário de Irina (Julia Bernat), que completa vinte anos. A irmã mais velha é Olga (Isabel Teixeira) e a do meio, Maria (Stella Rabello), que já está casada e já não vive mais na casa da família paterna.

Uma das características nucleares do trabalho é dada, de forma diferente em relação ao que já tinha se dado em projetos anteriores, pelo diálogo entre cinema e teatro como meios expressivos com características distintas. A peça a que assistimos é gravada todo o tempo. Há uma justificativa ficcional para isso. Irina desenvolveu o gosto e o hábito de filmar desde que ganhara

3 Neste número de Sala Preta, o leitor encontrará entrevista na qual a encenadora disponibiliza informações significativas sobre sua trajetória e ao longo da qual se abordam também vários dos temas contidos neste artigo. No que tange ao trabalho de Christiane Jatahy, pude acompanhá-lo desde o ano de 1987 quando ela integrou o elenco do espetáculo Édipo Rei, de Sófocles, dirigido por mim e realizado pelo Grupo Mergulho no Trágico, no Rio de Janeiro. Fontes de informação importantes sobre a encenadora estão nos sítios eletrônicos da Enciclopédia Itaú Cultural, Teatropedia e Cia Vértice, todos consultados em 20/10/2015.

$4 \mathrm{O}$ trabalho estreou no Espaço SESC-Copacabana (que é provido de diferentes salas de espetáculo e que se localiza no bairro de Copacabana, no Rio de Janeiro), em 2014, exibindo-se, no mesmo ano, em várias cidades da Europa com o título em inglês What if they went to Moscow? 
uma câmera de presente de seu pai, falecido há um ano e, agora, ela está imbuída do desejo de registrar em imagens a noite de seu aniversário. A partir daí, outras câmeras (que ecoam e amplificam o gesto da personagem), mas já não sendo operadas apenas pela atriz que encarna Irina, complementam a captação de imagens. O palco se constitui, assim, como uma espécie de set de filmagem.

As imagens editadas em tempo real pela diretora não são vistas pelos espectadores que assistem à peça. Elas são projetadas no telão localizado dentro de outro ambiente do mesmo edifício. Então, há dois coletivos, duas comunidades distintas de espectadores que se formam para assistir o trabaIho performático, seja por meio das imagens captadas e editadas ao vivo, seja por meio da atuação teatral presenciada em uma das duas salas em que se pode acompanhar a representação, alternativamente como teatro ou como cinema. O espectador necessita fazer a escolha pela peça ou pelo filme no ato de comprar o seu ingresso e, a partir daí, ele se dirige para um ou para outro ambiente, teatro ou cinema.

A perspectiva e a experiência de recepção são muito diversas em cada uma das duas possibilidades de acompanhamento da ação dramática. No caso do espetáculo teatral propriamente dito, não vemos imagens das atrizes projetadas, exceto em um momento final, quando elas estão na outra sala, na qual, ao longo do tempo de duração do espetáculo, os espectadores que optaram por assistir ao filme, acompanharam o trabalho por meio das imagens projetadas (com exceção desse momento final em que as atrizes se retiram uma a uma do espaço cênico e se dirigem para essa sala de projeção, na qual se dera, ao longo do tempo, uma apresentação muito semelhante à de um filme).

A percepção dos espectadores da peça propriamente dita responde a uma dinâmica de intensa teatralidade a que estão expostos. Essa dinâmica é constituída pela exploração da espessura e volume dos materiais e do espaço, a experiência relativa aos sons e música executados ao vivo, a mobilidade dos elementos constitutivos da cenografia, o das peças cenográficas como estruturas funcionais do jogo, ainda que tenham também um caráter representacional e que sirvam para construir a referência espacial da ação e da situação dramática. 
O cenário - concebido em parceria por Christiane Jatahy e por Marcelo Lipiani, que também é o responsável pela direção de arte e pela realização arquitetônica do dispositivo cenográfico - é estruturado por meio de uma série de praticáveis móveis, representando a porta da casa, pedaços verticais de paredes, cantos formados por junções dessas paredes etc. Esses praticáveis verticais são deslocados em vários momentos do espetáculo de quase duas horas de duração. Não aparecem juntos desde o início e não se mantêm da mesma forma do começo ao final do espetáculo. Em alguns momentos estão unidos e dão a sensação de totalidade do ambiente, para logo depois se moverem, como puras peças funcionais, quebrando a prioridade da representação integral, coerente e contínua da casa, para enfatizar, então, mais do que o ambiente representado, o lugar da representação.

A opção que se faz é por um tipo de representação parcial, lacunar e fragmentária. Essa opção se verifica nos diversos elementos da cenografia, como, por exemplo, na piscina, que é figurada por uma espécie de banheira transparente e colocada como uma peça isolada, quase sempre ao fundo do palco, mas deslocando-se para a frente do espaço cênico, na parte final do espetáculo. A inexistência de coxias ou tapadeiras laterais no espaço cênico colabora para que não se chegue a configurar um cenário de gabinete representando, de forma total e cerrada, o ambiente interno da casa.

Os doces e salgados, o vinho, a champanhe, o suco que são servidos na festa de aniversário de Irina e se oferecem também aos espectadores; o telefone fixo que toca persistentemente, enquanto vemos que cada uma das irmãs espera que a outra atenda o aparelho; as personagens que se inquietam se uma ou outra delas foi flagrada em momento de tristeza e parece ter chorado sozinha num canto são, dentre outros, alguns dos temas das conversas fragmentadas, das pequenas tramas e interações, tão cheias de pontos de interrupção, de repentinas mudanças de rumo a todo instante. Nenhum dos detalhes da interação das personagens se torna o ponto central de um conflito único de interesses ou de visões de mundo, ponto central sobre o qual se organizasse um possível embate que se aprofundasse pouco a pouco e que desse um foco unidirecional às ocorrências cênicas.

De fato, não há um conflito central, nem aparentemente existe uma intenção por parte da dramaturga e diretora de estabelecer um significado 
central para unificar e para orientar numa direção determinada os pequenos detalhes ou focos de atenção que mobilizam sucessivamente as personagens em cena. Tampouco há qualquer significado transcendental, de caráter ético ou político sobre a vida, a justiça, a verdade ou a sociedade, significado transcendental e orgânico esse que seja explicitado verbalmente ou, então, destacado pelo conjunto dos meios expressivos utilizados na encenação. Os detalhes, ao contrário, valem por si, são singularidades que se acumulam sem hierarquia. Geram conjuntos (comunidades) de elementos semânticos plurais, mas, como detalhes, eles não são suplantados por totalidades orgânicas (significados nucleares) que substituam os detalhes e os múltiplos instantes de ocorrências episódicas e singulares.

\section{Os espectadores atores}

No que diz respeito ao tipo de interação com o público, observa-se, em primeiro lugar, que as atrizes responsáveis por interpretar as três irmãs dirigem inúmeras vezes suas falas diretamente aos espectadores. Estes também são incluídos na situação cênica por meio da iluminação que, em grande parte do tempo, banha a todos (elenco e plateia) na mesma luminosidade, sem estabelecer fronteiras rígidas entre cena e sala. A inserção dos espectadores na ação dramática é feita igualmente em decorrência de receberem, por parte da dramaturgia e da encenação, um papel claro para ser jogado por eles. Trata-se do papel de convidados que vieram integrar-se às três irmãs, para comemorarem o aniversário da mais nova. Ação teatral essa que são levados a desempenharem ao lado de sua atividade como observadores dessa mesma ação.

A ênfase no puro teatro, no jogo, na interação, no instante em fuga é aprofundada por meio do apelo explícito aos espectadores para que joguem eles também, ainda que apenas das cadeiras que ocupam, uma vez que sua interação direta com as atrizes no próprio palco se dá em um único momento, no qual alguns dos espectadores aceitam participar da cena em que os convidados da festa são estimulados a dançarem na sala da família. O fato é que, o que se vê, por procedimentos diversos, é que o prazer da ficção como invenção (e como movimento, tempo, transformação, plasticidade, jogo e in- 
venção) - no processo mesmo de seu desdobramento enquanto performance - substitui o outro caráter da ficção, ou seja, a ficção como suporte de um efeito de real, de uma completude, de um referente e de um significado mais ou menos estável.

Os espectadores do filme recebem uma imagem mais ilusionista, mais dada à completude e à coerência do ambiente da ação do que o público do teatro. Há, de certo modo, uma totalização, uma estabilização da imagem da casa da família, conforme transmitida aos espectadores do filme. Nesse sentido, no palco, o que se vê são os elementos materiais, por meio dos quais se produz a ficção cinematográfica e o efeito de real para o público do filme.

É verdade, porém, que há formas de se flexibilizar, no próprio filme, esse efeito de real (o da apreensão da ficção como verdade, como narrativa supostamente verdadeira ou como registro de um fato recebido como tendo efetivamente ocorrido num passado mais ou menos remoto). Uma dessas formas são as atrizes falarem diretamente aos espectadores do filme, ao se dirigirem frontalmente para as câmaras, forma tradicional assumida pelo distanciamento de tipo brechtiano no cinema.

Entretanto, ao vermos no filme as personagens em seu ambiente, não presenciamos, por exemplo, a montagem cenográfica de um trecho do cômodo em que estão. Ao contrário, vemos as personagens contra uma parede, próximas a um móvel, sobre uma grama, encostadas em uma folhagem e entendemos que elas estão dentro da casa, no jardim etc. Nesse sentido é que o efeito de real e de ilusão é maior por meio das imagens editadas ao vivo pela diretora e projetadas na sala em que estão os espectadores que vêm a performance na versão filme.

\section{(Des)construção}

Há, na obra conjugada como peça e filme simultâneos, um nítido desejo de desconstrução da forma e da composição, de modo que os traços com que se desenham as personagens não omitam ou atenuem a presença das próprias atrizes, em favor da ênfase sobre as figuras ficcionais construídas. Mas, é preciso compreender que essa presença das próprias atrizes é trabalhada e é buscada também em uma estrutura formal de composição, por 
mais paradoxal que, a princípio, isso possa parecer, uma vez que destaco igualmente o desejo de desconstrução da forma. Mas o fato é que não se trata de um projeto de renúncia completa à forma e à representação em favor do que seria possivelmente a própria vida. Não é isso exatamente, mas, sem dúvida, há um desejo de atenuar não só a ênfase sobre as personagens, como também o peso formal de composição dos gestos, da emissão vocal e dos movimentos, em prol da emergência de traços e fluxos que se podem perceber como mais instantâneos.

Mas aí também há aspectos sutis que demandam compreensão mais refinada. Por meio de traços muito leves e tênues de composição das personagens, quase que meramente indicadas, mais do que dadas em sua completude, o que se produz não é propriamente uma presença contundente das atrizes como sujeitos fortes. Ao contrário disso, o que as intérpretes parecem apreender do método de construção de personagens em Tchekhov e explorarem no interior do trabalho conduzido por Christiane Jatahy é um jeito particular de lidar com a noção tênue e sutil de sujeito, seja no espaço do drama, seja no âmbito da vida.

Por essa razão, a formulação como a que fiz acima - dizendo que a peça enfatiza, em lugar das personagens, a presença das próprias atrizes - precisa ser relativizada. O que é esse próprio das atrizes que aparece no modo de elas estarem em cena? Não se trata, por exemplo, da propriedade de consciência e de intencionalidade de um sujeito totalmente presente a si mesmo em sua voz própria, em seu espírito ou consciência, em suas visões de mundo e suas ações. Ao contrário, a presença das próprias atrizes, diz respeito antes às suas eventuais fragilidades, a aspectos de sua subjetividade mais sutis e menos dominados pela imagem social do eu. É como se as intérpretes buscassem uma espécie de desnudamento no que tange às certezas, às convicções prévias, aos padrões habitualmente valorizados como uma imagem positiva do sujeito no mundo capitalista e na sociedade de consumo em que vivemos.

Nesse sentido o termo "próprio" não alude, no sintagma "presença das próprias atrizes", a uma natureza identitária específica, própria, que se queira afirmar a respeito do indivíduo na condição de ser dotado de consciência plena sobre si, como sujeito, e sobre o mundo, como objeto. De fato, as atrizes 
(ou as personagens que elas interpretam) são percebidas menos por suas posições do que por seu deslocamento, por um não encaixe territorial, social ou mesmo lógico-narrativo, como se elas se permitissem ser flagradas em uma dimensão de singularidade ante outros sujeitos, em meio ao instante fugidio do evento teatral. São percebidas menos por qualquer enraizamento identitário do que por um processo de desterritorialização em que se encontram. No instante fugidio, o presente se torna inatual em relação a si mesmo, ou melhor, as personagens inseridas na atualidade do tempo contemporâneo experimentam nele certo distanciamento, certa estranheza, certa sensação de não pertencimento e de não identidade.

O âmbito do comum que se institui pela qualidade específica de presença cênica das intérpretes principais e de sua interação com os espectadores parece só poder emergir a partir do tom menor, do pequeno gesto, do desejo pontual, da ação muito circunscrita ao ambiente e ao mundo em que se encontram as personagens, na ficção, bem como naquele em que convivem as atrizes e espectadores, ou seja, no espaço teatral. Nesse sentido, o que se marca é um modo particular de lidar com o outro e consigo mesmo, modo para o qual é importante que o sujeito (na condição ou não de artista) possa renunciar a preencher todos os espaços de construção, que, ao contrário, ele mantenha lacunas, lugares vazios, que não forneça apenas verdades fortes e completas, que trabalhe com uma parte de não saber, de modo a viabilizar um fluxo de afetos e sentidos que poderíamos chamar de menores, em cujo diapasão, os elementos pueris, os objetos parciais e sem importância da vida cotidiana possam transitar entre os sujeitos.

\section{Reinvenção}

Nada disso, porém, é explicitado diretamente nos conteúdos verbais das falas. Trata-se de temas que emergem da forma pela qual se constituem os fluxos da fala enquanto sopro e dos gestos enquanto impulsos. As pausas, as oscilações, o volume muitas vezes baixo e a qualidade de energia tanto da voz, quanto do movimento, têm mais a ver com quem segue um caminho tateando o terreno de forma incerta do que com quem segue seu percurso com a propriedade de uma direção totalmente determinada e segura. Na peça-filme 
de Christiane Jatahy, o teor político está ligado a uma proposição quanto ao modo possível de o sujeito estar presente e de tomar a palavra - seja na cena e na ficção, seja na vida e na sociedade - quanto à possibilidade de exposição ao outro, por meio da vulnerabilidade a esse outro e não por meio das verdades plenas daquele que se expõe.

Trabalha-se com a possibilidade de transfiguração do banal e do ordinário em instantes inesperados de fulguração, de invenção, de solidariedade e de criação. Trata-se de se abrir para um modo de subjetivação distinto da subjetivação estimulada pelo aparato do consumo e dos grandes meios de comunicação, modos dominantes de subjetivação esses que estão estreitamente ligados a uma concepção da felicidade como mercadoria.

É todo um jeito outro de estar no mundo, de estar em cena e de estar junto, de compartilhar o comum (no sentido do ordinário e do coletivo) que a própria qualidade de presença das atrizes parece propor ao espectador, convidando-o a se permitir estar, também ele, mais despojado para lidar com as próprias fragilidades e mais aberto ou vulnerável ao outro. Penso que certa informalidade da atuação das atrizes está ligada uma desconstrução deliberada da forma enquanto força ativa, para viabilizar fluxos singulares de subjetivação individual e coletiva, ligados a outra concepção de força, aberta à fragilidade, à passividade e à receptividade do que vem do exterior. É nesse sentido que a peça fornece também um material significativo para a reflexão sobre o teor político singular do teatro contemporâneo, associado a um jogo do dentro e do fora, do teatro e da vida, da espessura e da linha de fuga da cena teatral.

A intérprete de Olga, Isabel Teixeira, logo no início da peça-filme, diz o que se segue:

É como se a gente tivesse na beira do trampolim de uma piscina e a água embaixo, azul, cristalina, brilhando e o passado em fila empurrando a gente pra frente e, ao mesmo tempo, segurando o salto. E, depois do salto, um longo tempo no ar e os minutos que parecem ser eternos, porque mudar é como morrer um pouco, a gente nunca mais vai ser o mesmo. Talvez isso não seja uma peça. Talvez não seja um filme também. Talvez sejam as duas coisas ao mesmo tempo e é nesse espaço, nesse entre, que a gente vai tentar se reinventar 
De fato, os dois coletivos de espectadores, o do filme e o da peça, sabem que, nos dois casos, há um fora ao qual se alude de diversos modos. Aliás, filme e peça são, no projeto, o fora um do outro, ou melhor, são o fora, a diferença no interior de cada um desses âmbitos. É preciso perceber que esse fora, essa exterioridade, que se aborda na peça (personagens desenraizadas, atrizes sendo vistas de modo muito direto pelos espectadores, quase que por fora da vestimenta configurada pela personagem ficcional) é também constituído de um dentro, ou seja, o dentro do pequeno mundo ficcional que permite o jogo das relações, das interações e das exposições de uns aos outros, o dentro ou o interior do volume ou da espessura, a partir dos quais a experiência do devir e da vulnerabilidade ao outro se viabiliza para os espectadores do espetáculo teatral ou do filme que é gravado, editado e projetado ao vivo.

\section{Referências bibliográficas}

COSTA FILHO, J. da. O teatro de Sanchis Sinisterra: fronteira e mobilidade. 1997. Dissertação (Mestrado em Artes Cênicas) - Universidade Federal do Estado do Rio de Janeiro (UNIRIO), Rio de Janeiro, 1997.

CIA VÉRTICE. Disponível em: <http://christianejatahy.com.br/cia-vertice>. Acesso em: 20 out. 2015.

ENCICLOPÉDIA ITAÚ CULTURAL. Disponível em: <http://enciclopedia.itaucultural. org.br/pessoa426802/cristiane-jatahy>. Acesso em: 20 out. 2015.

TEATROPEDIA. Disponível em: <http://teatropedia.com/wiki/Christiane_Jatahy>. Acesso em: 20 out. 2015.

Recebido em 21/10/2015

Aprovado em 21/10/2015

Publicado em 21/12/2015 